\title{
Synthesis and glycosylation of CD52, the major 'maturation- associated' antigen of rat spermatozoa, in the cauda epididymidis
}

\author{
P. Derr ${ }^{1}$, C. H. Yeung ${ }^{2}$, T. G. Cooper ${ }^{2}$ and C. Kirchhoff ${ }^{1 *}$ \\ ${ }^{1}$ IHF Institute for Hormone and Fertility Research at the University of Hamburg, Germany; \\ and ${ }^{2}$ Institute of Reproductive Medicine of the University Münster, Germany
}

A western and lectin blot analysis was performed of the major 'maturation-associated' antigen of rat spermatozoa, which is the rat counterpart of human CD52. In the absence of a suitable antibody, direct study of this approximately $26 \mathrm{kDa}$ antigen, named previously SMemG, had been difficult. In the present study, these problems were overcome by raising a polyclonal antibody against a chemosynthetic peptide predicted from the cDNA sequence of the antigen. The antibody bound to a glycoprotein of rat cauda epididymidal tissue and spermatozoa, this glycoprotein was cleaved by phosphatidylinositol-specific phospholipase $\mathrm{C}$ and, after deglycosylation, was reduced to approximately $6 \mathrm{kDa}$. Northern blot analysis confirmed that the CD52 mRNA was transcribed only post-testicularly, and antibody binding to testicular and sperm proteins of different molecular masses was shown to be nonspecific. Flow cytometry also indicated that the antigen was inserted into the sperm membrane during epididymal transit. Moreover, despite the presence of CD52 mRNA in all parts of the rat epididymis, only the 'long' mRNA molecules of the cauda region were efficiently translated and the antigen glycosylated, indicating that expression of rat CD52 is regulated on a post-transcriptional level. Lectin binding and deglycosylation studies supported the contention that there is extensive mucin-type $\boldsymbol{O}$-glycosylation of rat CD52. In rats, there was no indication of complex $\mathrm{N}$-linked carbohydrates similar to those described for human CD52.

\section{Introduction}

Post-testicular remodelling of the sperm glycocalyx occurs within the epididymis (for a review, see Yanagimachi, 1994), and a considerable number of changes seem to be due to the uptake by spermatozoa of glycoproteins from epididymal secretions (for a review, see Kirchhoff, 1998). As an alternative mechanism, it has been suggested that modifications of carbohydrates of pre-existing sperm glycoproteins from the testis occur during epididymal transit, possibly catalysed by a variety of extracellular carbohydrate-modifying enzyme activities in the epididymal fluid and on the sperm surface (for a review, see Tulsiani et al., 1999). Rat CD52, previously named the 'major maturation-associated sperm membrane antigen' (Zeheb and Orr, 1984; Moore et al., 1989), an approximately $26 \mathrm{kDa}$ protein (Myles, 1993), and sperm membrane glycoprotein (SmemG) (Eccleston et al., 1994) may be an example of such a glycoprotein. Rat CD52 was originally identified as the principal molecule labelled by surface carbohydrate-labelling experiments using intact mature spermatozoa from the cauda epididymidis (Olson and Hamilton, 1978; Jones et al., 1981; Brown et al., 1983; Zeheb and Orr, 1984; Hamilton et al., 1986; Olson et al., 1987; Moore et al., 1989; Eccleston et al., 1994). Furthermore,

*Correspondence

Email: kirchoff@ihf.de carbohydrate labelling of rat sperm glycoproteins on western blots in vitro (Pera et al., 1997) showed an unexpectedly high selectivity: the only molecule accessible to the periodate oxidation reaction was the counterpart of CD52. Biochemical studies revealed that $>60 \%$ of this molecule consisted of carbohydrate (Eccleston et al., 1994).

Other studies have indicated that rat CD52 may undergo extracellular carbohydrate modification during epididymal transit, which explains its post-testicular disclosure on the sperm surface (for a review, see Myles, 1993). As a glycosylphosphatidyl-inositol (GPI)-anchored integral sperm membrane protein, it was initially assumed to be a preexisting component originating at spermatogenesis and that its carbohydrate moiety underwent extensive modification only at a later stage within the epididymal duct (Hamilton et al., 1986; Moore et al., 1989; Eccleston et al., 1994; for a review, see Myles, 1993). However, molecular cloning and in situ transcript hybridization proved that the CD52 mRNA is synthesized by the epididymal duct epithelium (Kirchhoff, 1994, 1996). This result indicates that uptake of the lipidanchored antigen by spermatozoa was one of the major events occurring to sperm plasma membrane during epididymal transit (Kirchhoff and Hale, 1996). In several mammalian species, including humans, it has been shown that CD52 mRNA is produced only post-testicularly, and not by spermatogenic cells within the testis (Kirchhoff et al., 1993; Krull et al., 1993; Pera et al., 1994; Kirchhoff, 1994, 1996). The glycopeptide is produced by the epididymal 
(a)

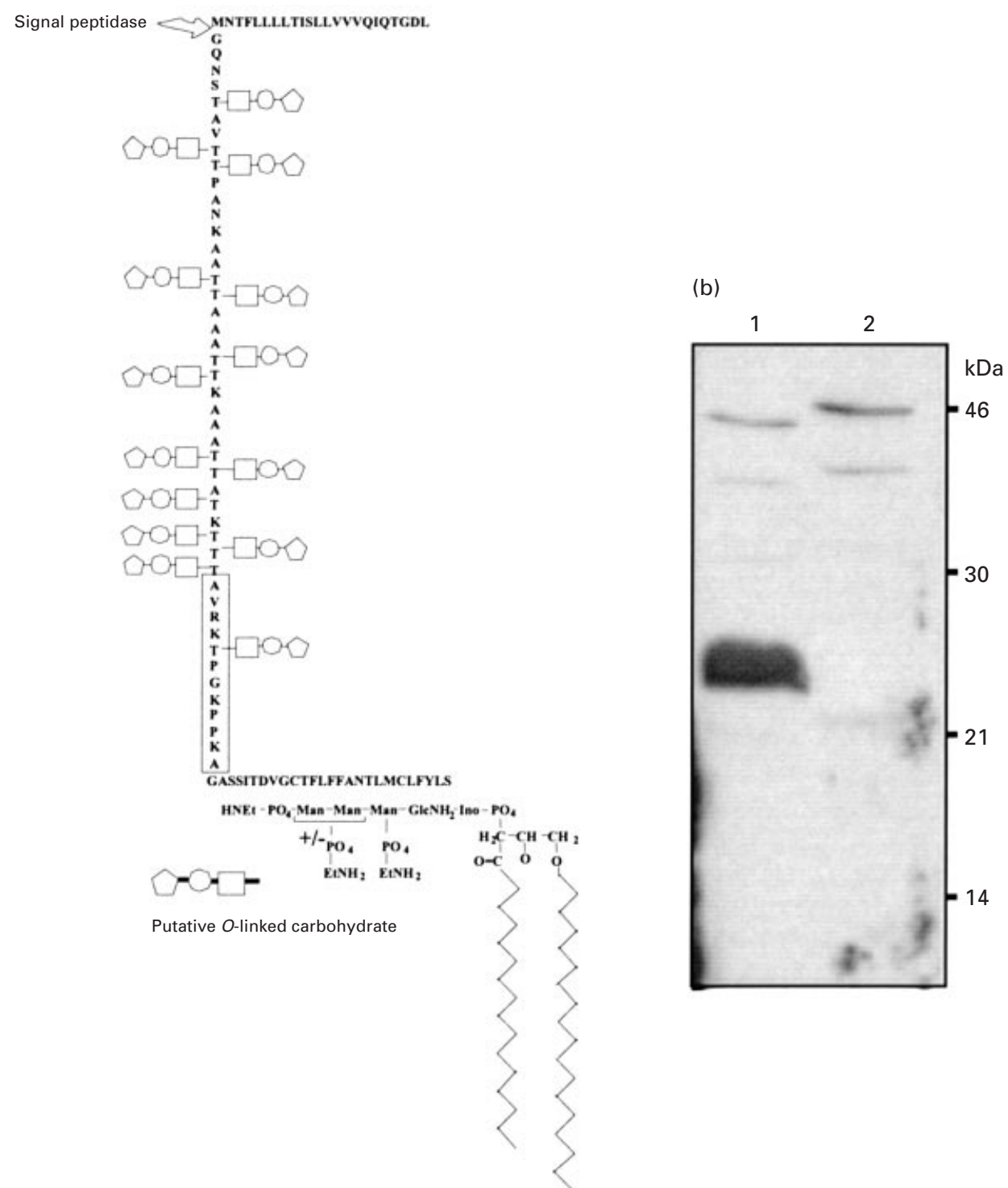

(c)

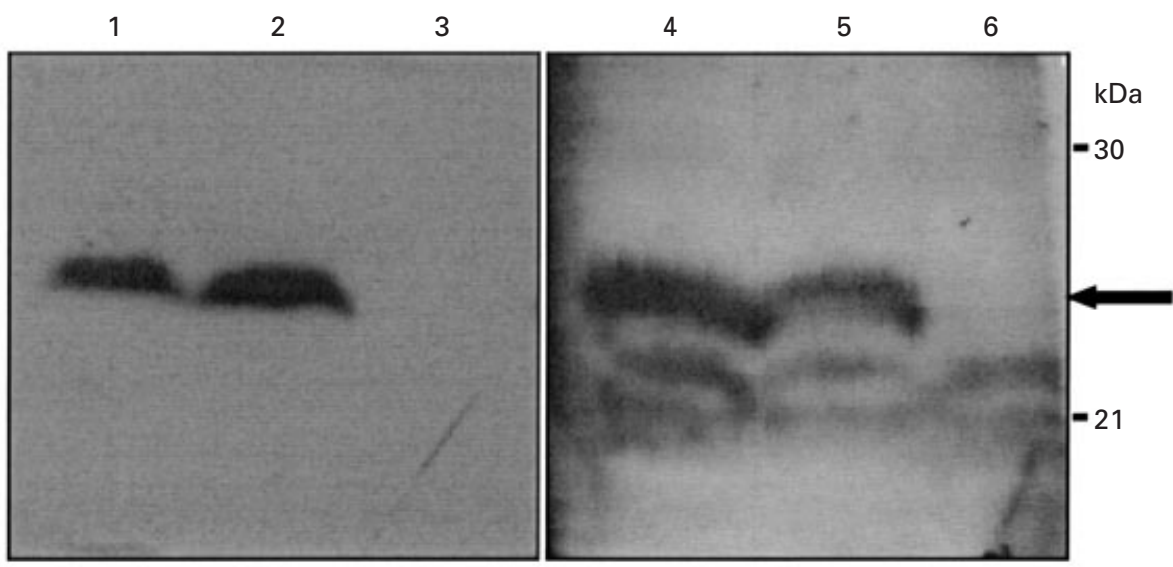

Fig. 1. Characterization of polyclonal anti-CD52 antibody specificity. (a) Putative structure of rat CD52 as predicted from its cDNA. The mature peptide sequence is arranged vertically. A 12-mer peptide sequence chosen for antibody production is boxed; putative $\mathrm{O}$ glycosylation sites are shown by the open symbols; N-terminal and C-terminal signal peptides are arranged horizontally. A standard 
duct epithelium and transferred to the sperm membrane with its lipid anchor intact (Yeung et al., 1997).

Another important feature of the expression of epididymal CD52 is its regional specificity: maximum mRNA content is found in the distal part of the epididymis in various mammalian species (Krull et al., 1993; Pera et al., 1994). Furthermore, in the rat epididymis there is a region-specific variation in the length of the CD52 mRNA poly(A) tail (Pera et al., 1997). Although 'short' CD52 mRNA was present in all parts of the epididymis, only the cauda epididymidis contained 'long' CD52 mRNA carrying an extended poly(A) tail. This finding indicated that regulation of the expression of CD52 in rats occurs on a post-transcriptional level; however, this contention was difficult to prove in the absence of a suitable antibody (Pera et al., 1997). Moreover, carbohydrate modification of rat CD52 during epididymal transit could not be excluded (Pera et al., 1997). Therefore, a reinvestigation of rat epididymal CD52 synthesis and glycosylation was undertaken using an antipeptide antiserum.

\section{Materials and Methods}

\section{Materials, tissues and animal experiments}

Chemicals were obtained from Sigma Deisenhofen, Germany, unless otherwise stated. Sprague-Dawley male rats (Charles River, $408 \pm 28$ g body weight) were housed under a $12 \mathrm{~h}$ light: $12 \mathrm{~h}$ dark photoperiod, and had access to rat chow (Altromin $\mathrm{GmbH}$, Lage) and water ad libitum. Animal experiments were performed as described by Pera et al. (1997). Briefly, for various types of surgery animals were anaesthetized by injection of $20 \mathrm{mg}$ sodium pentobarbital $\mathrm{kg}^{-1}$ (Nembutal) or inhalation of halothane (Hoechst, Frankfurt/Main) and surgery was performed through a midline abdominal incision for bilateral castration, efferent duct ligation, and the establishment of unilateral cryptepididymis, combined with either bilateral castration or dissection of efferent ducts as described by Pera et al. (1997). After 2 weeks, the animals were killed by $\mathrm{CO}_{2}$ asphyxiation and the testes and epididymides were removed immediately. Epididymides were cut into caput, corpus and cauda epididymides. Control tissues were taken from untreated animals. Tissues were shock-frozen in liquid nitrogen and stored at $-80^{\circ} \mathrm{C}$.

\section{Collection of epididymal spermatozoa and fluid for protein extraction}

Spermatozoa and fluid from the cauda epididymides were collected by cannulation of the proximal vas deferens with a 27-gauge needle connected to a polyvinyl chloride (PVC) catheter and retrograde perfusion of the tubule using PBS. The PVC catheters had been pulled out over a flame such that they tapered at one end to an outer diameter small enough to fit the size of the lumen of the vas deferens, and were tied in place by a 7/0 silk ligature. Luminal contents were flushed out gradually and were drawn into a positive displacement pipette as they exuded from the cut end of the tubule at the proximal cauda epididymidis. Spermatozoa and fluid from the cauda epididymidis were collected from lobules of mid-caput tubule by a similar technique using pulled-out PVC catheters with fine tips for insertion into the caput tubule. The luminal contents collected were dispersed into 0.1 or $0.5 \mathrm{ml} \mathrm{PBS}$ (for caput and cauda epididymidis, respectively) and the diluted fluid separated from the spermatozoa by centrifugation at $4000 \mathrm{~g}$ for $1 \mathrm{~min}$ and subsequently at $12000 \boldsymbol{g}$ for $2 \mathrm{~min}$. Sperm pellets were washed three times with PBS by centrifugation at $2000 \mathrm{~g}$ for $1 \mathrm{~min}$. Sperm-free fluid and spermatozoa were stored at $-80^{\circ} \mathrm{C}$. Although the cannulation and perfusion method enabled collection of uncontaminated luminal fluid, the yield of spermatozoa from the caput epididymidis was very low as only a short length of caput tubule could be perfused at a time because of the build up of perfusion pressure in the highly convoluted tubule. Therefore, an alternative method was used to increase the number of spermatozoa collected from the caput epididymis. The whole capita were decapsulated and cleaned of blood vessels. Spermatozoa were released into PBS by coarse mincing and applying gentle pressure to the tubules. Tubule fragments were removed by centrifugation at $300 \mathrm{~g}$ for $10 \mathrm{~s}$. Spermatozoa obtained in the supernatant were washed three times as described above. For the collection of testicular spermatozoa, efferent ducts were tied off close to the testes on both sides under halothane anaesthesia without causing damage to the vasculature. The rats were killed $20 \mathrm{~h}$ later by $\mathrm{CO}_{2}$ asphyxiation and the turgid testes were removed. The fine tip of a $50 \mu \mathrm{l}$ glass capillary tube, made by drawing out one end over a flame, was inserted into the avascular zone of the extratesticular rete to allow spermatozoa and rete testis fluid to flow into the capillary tube.

\section{Digestion of sperm proteins by phospholipase C}

Epididymides were separated into proximal and distal parts, cut with iridectomy scissors and suspended in Dulbecco's PBS containing $0.2 \mathrm{mmol}$ phenylmethanelsulfonyl fluoride (PMSF) $\mathrm{I}^{-1}$. Spermatozoa from the proximal part (named caput spermatozoa) and the distal part (named

phospholipase C-sensitive mammalian GPI anchor structure is proposed. (b) Specificity of antibody binding was shown by western blot analysis with antiserum of crude cauda epididymidal tissue protein extracts before (lane 1) and after (lane 2) competition with the chemosynthetic CD52 peptide. A major band is present at approximately $26 \mathrm{kDa}$, which is competed for by the peptide. (c) Phosphatidylinositol-specific phospholipase C (PI-specific PLC) digestion of the $26 \mathrm{kDa}$ protein (arrow) as analysed by western blot analysis (lanes 1-3) and glycoconjugate labelling (lanes 4-6). Lanes 1 and 4: cauda epididymidal sperm protein extract; lanes 2 and 5: cauda epididymidal sperm extract incubated for $2 \mathrm{~h}$ at $37^{\circ} \mathrm{C}$ without PI-specific PLC; lanes 3 and 6: extract incubated for $2 \mathrm{~h}$ at $37^{\circ} \mathrm{C}$ with PI-specific PLC. 
cauda spermatozoa) were collected and treated with phosphatidylinositol-specific phospholipase C (PI-specific PLC; Sigma; Type III) as described by Moore et al. (1989). Briefly, the number of spermatozoa was determined and the sample was divided into aliquots, each containing approximately $2 \times 10^{7}$ to $1 \times 10^{8}$ spermatozoa. Sperm samples were incubated with $20 \mathrm{U}$ PI-specific PLC for $2 \mathrm{~h}$ at $37^{\circ} \mathrm{C}$. Comparable sperm samples were incubated at $37^{\circ} \mathrm{C}$ without the enzyme as a control.

\section{RNA extraction and northern blot analysis}

RNA extraction and northern blot analysis were performed as described by Pera et al. (1996, 1997). Sequences of oligonucleotide primers used for the preparation of a DIG-labelled RB7/CD52 550 bp probe were 5'-AGTGGCCTGCAGACTGTCCT-3' and 5'TTATTGTGCCCTAGCTGGGT-3'.

\section{Western blot analysis, lectin binding and detection of immobilized glycoconjugates}

A 12-mer oligopeptide (see Fig. 1) was chosen as immunogen and, after coupling to keyhole limpet haemocyanin $(\mathrm{KLH})$, was used to produce a polyclonal antiserum in guinea-pigs (Pineda Antikörper Service, Berlin). The oligopeptide was used as an antigen to obtain affinitypurified antibodies. Protein extracts were prepared from pulverized epididymal tissue or washed spermatozoa as described by Pera et al. (1997), dispensed in equal aliquots and stored at $-80^{\circ} \mathrm{C}$. Methanol-chloroform (Folch) extracts of protein samples were prepared as described by Schröter et al. (1999). Samples of protein or Folch extract $(2-10 \mu \mathrm{l})$, depending on the number of spermatozoa or protein content as determined with the Protein Assay Kit No.1 (Biorad, München), were loaded on to $15 \%$ (w/v) polyacrylamide Laemmli-gels, and the proteins separated and transferred to PVDF membranes (Amersham, Braunschweig) as described by Schröter et al. (1999). Anti-CD52 antiserum from guineapigs was applied at a dilution of $1: 1000$ and purified antibody at $1.85 \mathrm{mg} \mathrm{ml}^{-1}$. Biotinylated Arachis hypogaea lectin (PNA), Maackia amurensis lectin (MAA), Sambucus nigra lectin (SNA), Concanavalia ensiformis lectin (Con A), Datura stramonium lectin (DSA) and Phaseolus vulgaris lectin (PHA-E) (all from Oxford GlycoSystems, Abingdon) were used at a dilution of $1 \mu \mathrm{g} \mathrm{ml}^{-1}$. For carbohydrate labelling in vitro, membranes were processed as described by Pera et al. (1997). Primary binding was detected using peroxidase-coupled secondary antibodies $\left(0.4 \mu \mathrm{g} \mathrm{ml}^{-1}\right)$. Alternatively, anti-DIG-Fab-POD (150 U ml-1, RocheBoehringer Mannheim) was used at a dilution of 1:1000 in 100 mmol Tris-Cl I-1 ${ }^{-1} \mathrm{pH} 7.5,150$ mmol sodium chloride $\mathrm{I}^{-1}$ and $1 \%(\mathrm{w} / \mathrm{v})$ blocking reagent. Chemiluminescence film detection was carried out using the SuperSignal ${ }^{T M}$ CL-HRP substrate system (Pierce Chemical Company, Rockford) according to the instructions of the supplier. Exposure was to
Fuji X-ray film. Specificity of antibody binding was shown by competition with the chemosynthetic peptide, incubating the guinea-pig antibody (1:1000 dilution) with the peptide at a final concentration of $100 \mu \mathrm{g} \mathrm{ml} \mathrm{m}^{-1}$.

\section{Immunocytochemical staining and flow cytometry of spermatozoa}

The capsule of the epididymis was slit open in each region studied to expose a lobule of tubule. The lobule was washed to remove the blood, cut free and placed in a drop of medium (bicarbonate buffered, supplemented with glucose, lactate and pyruvate; see Yeung et al., 1992) on a small plastic spatula. The isolated epididymal tubule segment was cut further to release the spermatozoa. After the spermatozoa were transferred and dispersed in $200 \mu \mathrm{l}$ medium in a tube at $37^{\circ} \mathrm{C}$ for $2 \mathrm{~min}$, a $2 \mu \mathrm{l}$ aliquot was diluted with the medium and used for determining the percentage of motile spermatozoa. Another $10 \mu \mathrm{l}$ aliquot was diluted with PBS and absorbance at $450 \mathrm{~nm}$ was measured to estimate sperm concentration. Testicular spermatozoa were collected from the rete testis as described above. Spermatozoa were washed with PBS containing $4 \mathrm{mg} \mathrm{BSA} \mathrm{ml} \mathrm{m}^{-1}$ and resuspended to $2 \times 10^{7} \mathrm{ml}^{-1}$. For each staining, $2.5 \mu \mathrm{l}$ rabbit serum was added as a blocking agent to $40 \mu \mathrm{l}$ washed spermatozoa and incubated for $10 \mathrm{~min}$ at room temperature before the addition of the antiserum, pre-immune or normal guinea-pig serum at a final dilution of 1:30 for a further 25 min of incubation. Spermatozoa were washed twice with $1 \mathrm{ml}$ PBS-BSA by centrifugation at $450 \mathrm{~g}$ for $5 \mathrm{~min}$ and resuspended in $45 \mu \mathrm{l}$ PBS-BSA before incubation with $5 \mu \mathrm{l}$ fluorescein isothiocyanate (FITC)-conjugated rabbit antiguinea-pig lgG (final dilution 1:100) for $30 \mathrm{~min}$ in the dark. After washing and resuspension in $300 \mu$ PBS-BSA, a total of about 5000 spermatozoa was analysed for green fluorescence emission at 505-545 nm with excitation at $488 \mathrm{~nm}$ using the Epics XL flow cytometer (Coulter, Krefeld) with forward scatter and side scatter signals to set gatings for spermatozoa. For light microscopy, stained spermatozoa were pelleted by centrifugation at $450 \mathrm{~g}$ for $5 \mathrm{~min}$ and dried on to glass slides, mounted with anti-fade mounting medium and observed using a Olympus BX-40 microscope with excitation filter BP450-480 and emission filter BA515.

\section{Desialylation and deglycosylation reactions}

Chemical desialylation and $\beta$-elimination of blotted glycoproteins were performed as described by Duk et al. (1997). For the cleavage of putative $\mathrm{N}$-glycans, crude protein extracts from rat cauda epididymidal fluid collected as described above were denatured in $0.1 \mathrm{~mol}$ mercaptoethanol $\mathrm{I}^{-1}$ and $0.5 \%(\mathrm{w} / \mathrm{v}) \mathrm{SDS}$, and digested overnight at $37^{\circ} \mathrm{C}$ with $5 \mathrm{mU} \mathrm{N}$-glycosidase $\mathrm{F} \mathrm{ml}^{-1}$ (Roche-Boehringer Mannheim). Complete deglycosylation of proteins was carried out using the Glyco Free Deglycosylation Kit (Kit K 500, Oxford Glyko Systems Ltd, Abington) according to the instructions of the suppliers. 


\section{Results}

\section{Western blot analysis of the rat CD52 antigen}

A chemosynthetic peptide was chosen as an immunogen, comprising 12 amino acid residues of the rat CD52 Cterminus (Kirchhoff, 1994, 1996; Fig. 1a). In this region of the peptide backbone, only one putative $O$-glycosylation site is predicted by the NetOglyc program (Hansen et al., 1998). Database searches using BLAST (Altschul et al., 1997) detected no similarities to peptides other than rat CD52. Western blot analysis was performed using protein extracts of whole cauda epididymidal tissue from adult rats and revealed one prominent immunostained band of approximately $26 \mathrm{kDa}$ (Fig. 1b). Specificity of the immune reaction was confirmed using the chemosynthetic oligopeptide to compete for antibody binding before western blot analysis. The immunostained band was also prominent in protein extracts of spermatozoa from rat cauda epididymidis. However, the band was not observed when intact rat spermatozoa were treated with Pl-specific PLC before protein extraction and western blot analysis (Fig. 1c), supporting other reports on GPI anchoring of the antigen (Moore et al., 1989; Eccleston et al., 1994). Congruent results, albeit with a more intense background staining, were obtained using the in vitro carbohydrate labelling technique (Fig. 1c), which also detected a major Pl-specific PLCsensitive glycoconjugate of approximately $26 \mathrm{kDa}$ in rat cauda spermatozoa (for a comparison, see Pera et al., 1997).

The CD52-related antigen was also present in high concentrations in cauda epididymidal fluid. Direct electro- phoretic comparison of the antigen from spermatozoa from cauda epididymidis and cauda fluid revealed a small but reproducible difference in electrophoretic mobility, in which the sperm antigen migrated at a slightly slower rate (Fig. 2a). However, this difference was not observed or was even reversed when the antigen from both sources was partially purified by methanol-chloroform (Folch) extraction before gel electrophoresis and western blot analysis (Fig. 2b; for a comparison, see Schröter et al., 1999), which does not support the contention that there are structural differences. It is possible that the lipid extraction destroyed hydrophobic interactions of the antigen with other membrane constituents of spermatozoa, thereby increasing its electrophoretic mobility.

Intense immunostaining of the antigen of approximately $26 \mathrm{kDa}$ was observed only in protein extracts of cauda epididymidal spermatozoa and cauda epididymidal tissue, whereas protein extracts of testicular and caput spermatozoa as well as extracts from epididymidal tissue of more proximal regions were negative (Fig. 3). Spleen protein extracts were also negative. However, occasionally, staining of an additional 15-17 kDa protein band was observed and was most prominent in sperm protein extracts. $\mathrm{N}$-terminal peptide sequencing of the two major protein constituents of this band (Toplab, München; data not shown) revealed that this staining was nonspecific and ruled out any relationship with the CD52 antigen. The data indicate nonspecific crossreaction with two proteins present in spermatozoa: cytochrome C oxidase (Goto et al., 1989) and testis lipidbinding protein (Pouresmaeili et al., 1997). (a)

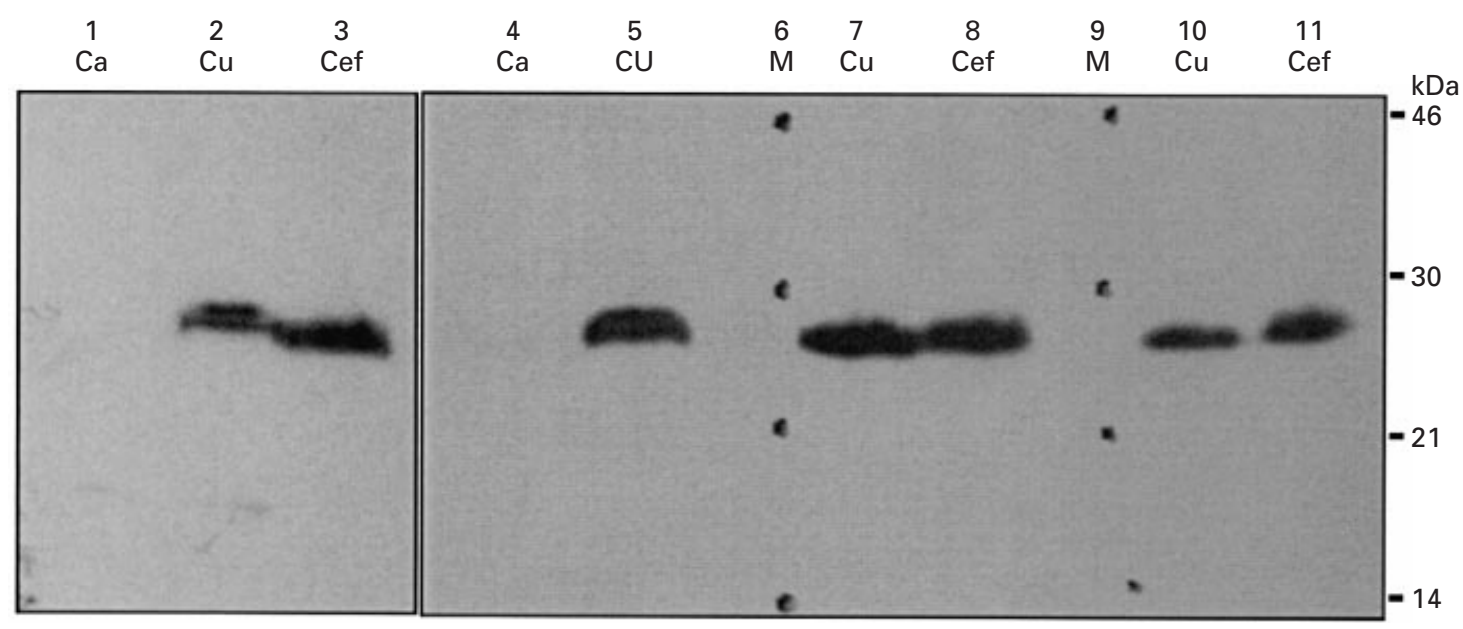

Fig. 2. Western blot analysis using purified antibody of CD52-related antigen in crude protein extracts (a) and Folch-extracts (b) of rat spermatozoa recovered from different regions of the male genital tract and from cauda epididymidal fluid. (a) Analysis of crude protein extracts. Lane 1: caput epididymidal sperm proteins (Ca); lane 2: cauda epididymidal sperm proteins (Cu); lane 3: proteins extracted from cauda epididymidal fluid (Cef). (b) Analysis of Folch-extracted samples. Lane 4: caput epididymidal sperm proteins (Ca); lanes 5, 7 and 10: cauda epididymidal sperm proteins (Cu); lanes 6 and 9: molecular mass marker proteins (M); lanes 8 and 11: proteins extracted from cauda epididymidal fluid (Cef). 
(a)

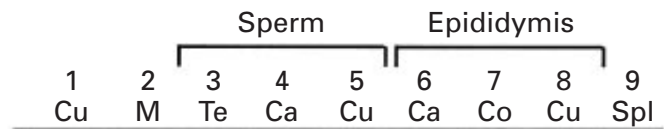

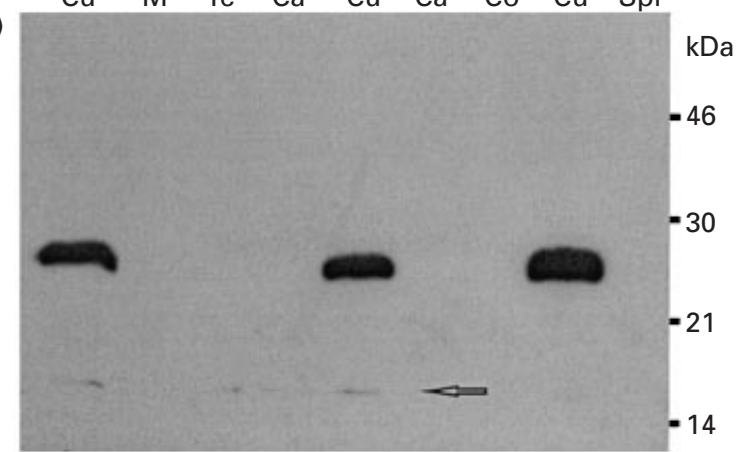

(b)

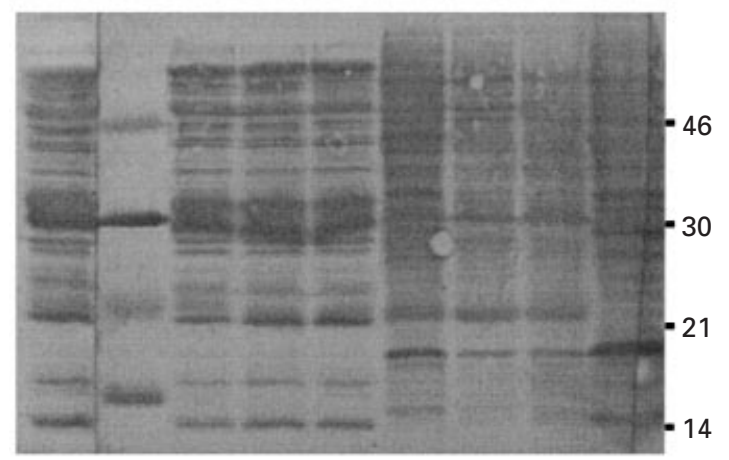

Fig. 3. Western blot analysis of CD52 antigen in protein extracts of rat spermatozoa recovered from different regions of the male genital tract and from whole tissue samples. (a) Lane 1: cauda sperm proteins $(\mathrm{Cu})$; lane 2: molecular mass marker proteins $(\mathrm{M})$; lane 3: testicular sperm proteins (Te); lane 4: caput sperm proteins $(\mathrm{Ca})$; lane 5 : cauda sperm proteins $(\mathrm{Cu})$; lane 6 : caput proteins $(\mathrm{Ca})$; lane 7: corpus proteins (Co); lane 8: cauda proteins $(\mathrm{Cu})$; lane 9: spleenic proteins (Spl). Arrow indicates a 15-17 kDa protein band that occasionally reacted with the antibody. (b) Corresponding Coomassie blue stained protein blot with similar amounts of proteins loaded in all lanes.

\section{Post-transcriptional regulation of the expression of CD52}

CD52 mRNA was confirmed to be produced only posttesticularly (Fig. 4a). However, although the mRNA appeared to be present in all parts of the rat epididymis in relatively high concentrations, staining of the glycoconjugate of approximately $26 \mathrm{kDa}$ and the corresponding protein band was observed only in the cauda epididymis (Fig. 4b,c), coinciding with the occurrence of 'long' CD52 mRNA molecules. Abdominal positioning of the epididymis, the socalled cryptepididymis (Bedford, 1978; Foldesy and Bedford, 1982; Pera et al., 1997), resulted in a small reduction in the amounts of both 'long' cauda epididymidal CD52 mRNA and the antigen of approximately $26 \mathrm{kDa}$ compared with 'normal' scrotal epididymides of sham-operated rats (Fig.
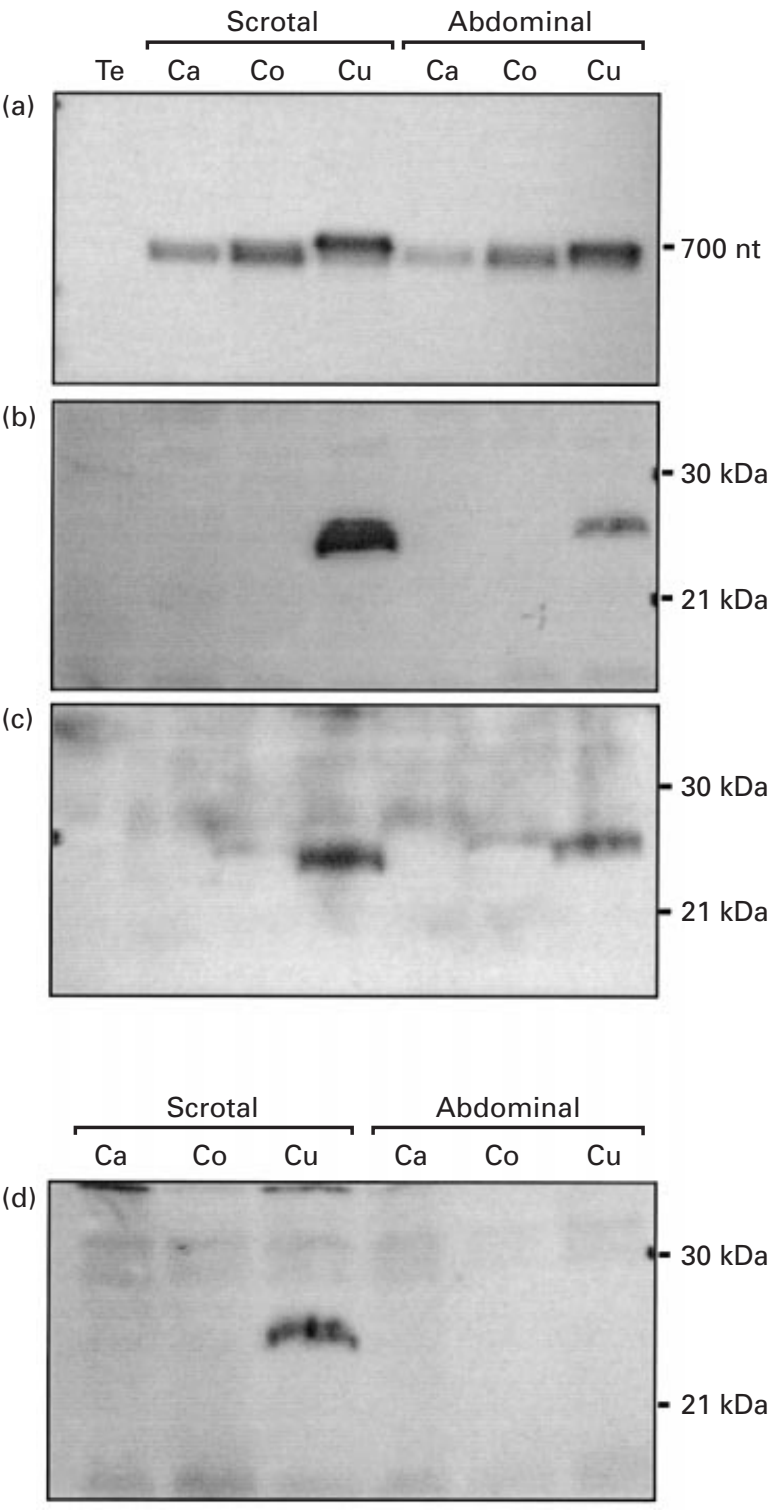

Fig. 4. Expression of CD52 in the rat epididymis after different treatments as analysed by northern blot analysis (a), western blot analysis (b,d) and in vitro glycoconjugate labelling (c). (a-c) Results obtained in unilateral cryptepididymal rats (scrotal and abdominal side, respectively) at 14 days after treatment; (d) results obtained from cryptepididymal rats that had also been castrated for 14 days (scrotal and abdominal side). Ca: caput epididymidis; Co: corpus epididymidis; Cu: cauda epididymidis; Nt: nucleotides; Te: testis. Similar amounts of RNA or protein, respectively, were loaded in each lane.

$4 b, c)$. The cryptepididymal condition combined with the castration of animals, which has been shown to abolish CD52 mRNA completely (Pera et al., 1997), also completely abolished the corresponding cauda epididymidal antigen (Fig. 4d), thus extending and confirming the results of Pera et al. (1997) at the peptide level. 
Immunostaining and flow cytometric measurements of rat epididymal spermatozoa

Indirect immunofluorescence revealed that most spermatozoa recovered from the cauda epididymidis (73-95\%) showed strong fluorescence over their entire surface (Fig. 5). Flow cytometric analysis confirmed that in the more proximal regions, the percentage of stained spermatozoa was significantly lower (Fig. 6), although large individual variations were observed. Heterogeneity of antibody binding among immature spermatozoa was also reflected by the flow cytometric analysis, showing the distribution of two populations of spermatozoa or a broad distribution peak in contrast to a narrow peak from the cauda spermatozoa (Fig. 6). Testicular sperm preparations consistently showed about $50 \%$ stained cells, which unlike the cauda epididymidal spermatozoa showed staining of the post-acrosomal head region in addition to some midpiece staining (Fig. 5). In the negative control that was stained using the preimmune guinea-pig serum, testicular spermatozoa gave a more intense background staining than mature cauda epididymidal spermatozoa.

\section{Lectin binding and deglycosylation of rat CD52}

A range of lectins as well as deglycosylation reactions were used to investigate possible $\mathrm{N}$ - and $\mathrm{O}$-glycosylation of the CD52 antigen. Strong binding of MAA in the range of the approximately $26 \mathrm{kDa}$ immunostained band of untreated rat tissue and sperm protein extracts is shown (Fig. 7), whereas
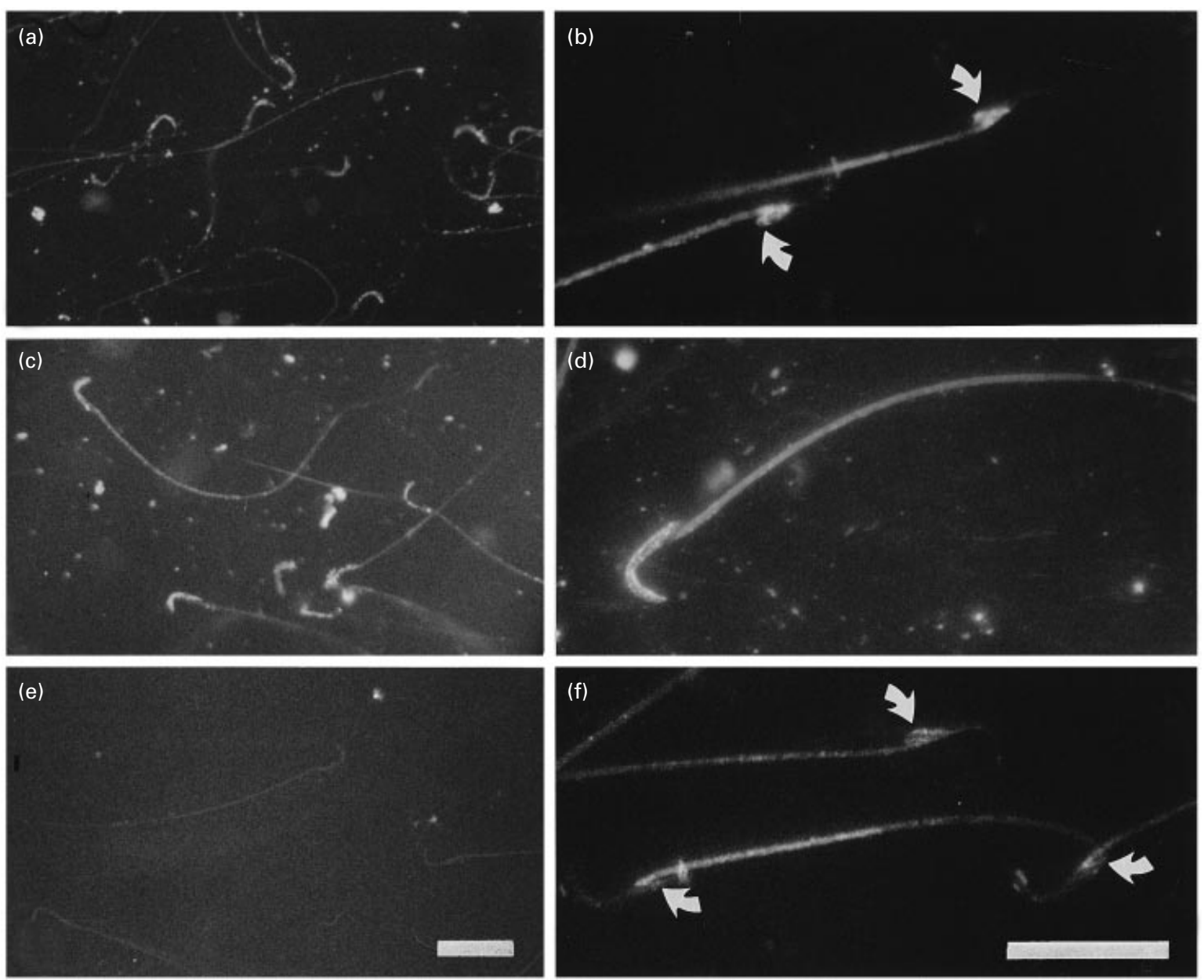

Fig. 5. Indirect fluorescein isothiocyanate (FITC) immunofluorescence of freshly washed non-fixed rat spermatozoa recovered from various regions of the male genital tract. Caput epididymidal spermatozoa (a) and cauda epididymidal spermatozoa (c), both stained with the polyclonal anti-CD52 antiserum and (e) cauda epididymidal spermatozoa reacted with negative control serum. Higher magnification illustrates the difference between staining patterns obtained with testicular and cauda epididymidal spermatozoa. Testicular spermatozoa (b) incubated with antiserum showed unstained heads (arrows), but occasional staining of the post-acrosomal region in addition to some irregular mid-piece staining, whereas staining of cauda epididymidal spermatozoa (d) with the antiserum appeared strong and homogeneous over the whole sperm surface, including the entire head, mid-piece and tail. Testicular spermatozoa ( $\mathrm{f}$ ) incubated with control serum showed post-acrosomal plus mid-piece staining (arrows). Scale bars represent $20 \mu \mathrm{m}$. 


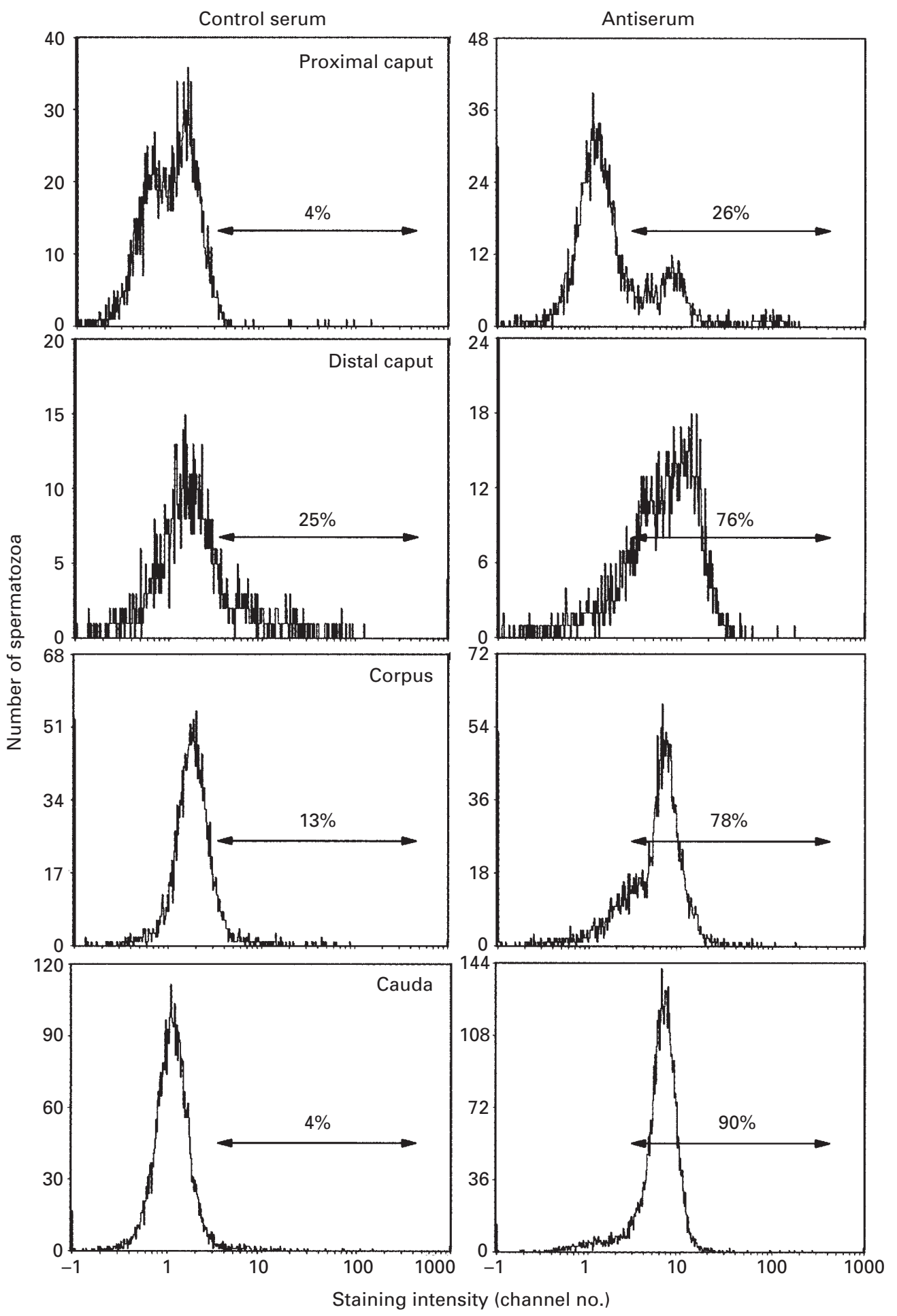

Fig. 6. Flow cytometry histograms of representative samples of spermatozoa recovered from the rat epididymis showing the distribution of fluorescence intensity of individual sperm cells (abcissa) stained with the polyclonal anti-CD52 antibody (right panels) or pre-immune guinea-pig serum as control (left panels). Percentages shown refer to spermatozoa within the gating (double-headed arrows), which distinguish positive staining from control staining (background). The net percentage of stained cells for each sample is obtained by subtraction of the respective control value. Note the small shift of peak intensity to the left from immature to mature spermatozoa, reflecting a decrease of unspecific sperm staining by the pre-immune serum control. 


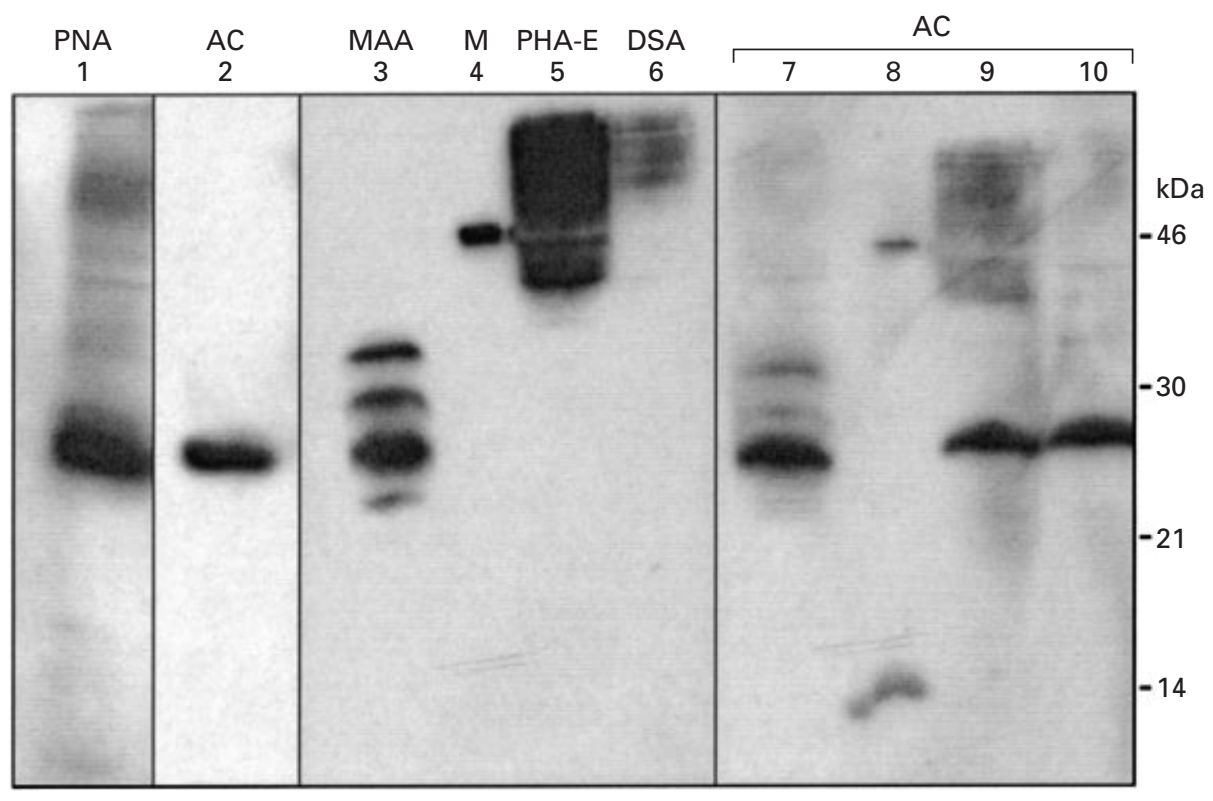

Fig. 7. Lectin binding studies of rat epididymal tissue protein extracts followed by subsequent western blot analyses of the CD52 antigen. Lane 1: binding pattern of Arachis hypogaea lectin (PNA) to epididymal protein extracts after desialylation; lane 2: antibody control (AC) of the same blot; lane 3: Maackia amurensis lectin (MAA) binding of epididymal proteins; lane 4: marker proteins (M); lane 5: Phaseolus vulgaris lectin (PHA-E); and lane 6: Datura stramonium lectin (DSA) binding of epididymal proteins; lanes 7-10: anti-CD52 antibody control (AC) of the blot (lanes 3-6).

other lectins did not bind specifically to a protein in this molecular mass range. After chemical desialylation of the protein blot (Duk et al., 1997), PNA bound to a protein of this molecular mass, whereas the other lectins did not. A summary of the lectin binding results is provided (Table 1), which predict $O$-linked, $\alpha 2-3$-sialylated carbohydrates and do not support the presence of large and complex $N$-linked glycans. This contention was corroborated by attempts to cleave putative $\mathrm{N}$-linked glycans enzymatically. Protein preparations from rat cauda epididymidal fluid and spermatozoa were subjected to PNGase F digestion before electrophoresis. No change in either microheterogeneity or electrophoretic mobility was observed by western blot analysis, even after overnight incubation with the enzyme (Fig. 8a; lanes 1-2). In a parallel experiment, using the human 15-25 kDa CD52 antigen (Schröter et al., 1999), loss of the large and heterogeneous $\mathrm{N}$-linked glycans was reflected by a marked loss of antigen heterogeneity combined with an increase in electrophoretic mobility (Fig. 8a; lanes 3-4), showing the effectiveness of the enzyme reaction used.

Complete deglycosylation of the rat antigen of approximately $26 \mathrm{kDa}$ by $\beta$-elimination (Duk et al., 1997) was attempted to remove all carbohydrate side chains, including $O$-linked glycans. After the two-step deglycosylation procedure, during subsequent western blot analysis a shift to significantly higher electrophoretic mobilities was observed. In addition to a broad smear, an immunostained band at approximately $6 \mathrm{kDa}$ was observed (Fig. 8b) which is in agreement with the calculated molecular mass of the unmodified rat CD52 peptide backbone. This finding indicated that deglycosylation of the antigen had been achieved (see also Bergeron et al., 1997), although partial degradation of the peptide backbone could not be excluded.

\section{Discussion}

Rat CD52, named previously as the major 'maturationassociated' antigen, was shown to correspond to a major sperm membrane antigen with an $M_{\mathrm{r}}$ of approximately 26000 , which was produced and glycosylated only by the distal epididymis. The late occurrence of the antigen indicates a functional association with sperm storage rather than with sperm maturation. The present study confirmed and extended previous results (Pera et al., 1997) that CD52 association of spermatozoa is cauda-specific. The glycopeptide was also detected in high concentrations in rat cauda fluid, and results from the present study indicate uptake by spermatozoa during epididymal transit, possibly as a GPI-anchored antigen (for a comparison, see Kirchhoff et al., 1996; Yeung et al., 1997). Olson et al. (1987) reported that rat caput spermatozoa take up a major $26 \mathrm{kDa}$ protein from cauda epididymidal fluid in vitro. Furthermore, related 
Table 1. Lectin binding properties of an immunoreactive protein of approximately $26 \mathrm{kDa}$ from rat cauda epididymidal tissue and spermatozoa

\begin{tabular}{|c|c|c|c|}
\hline Lectin & $\begin{array}{l}\text { Cauda epididymidal } \\
\text { tissue protein }\end{array}$ & $\begin{array}{l}\text { Cauda epididymidal } \\
\text { sperm protein }\end{array}$ & Specificity and linkage \\
\hline PNA & $+^{*}$ & $+^{*}$ & $\beta$-Gal, Gal $\beta 1-3$ GalNAc, O-linked \\
\hline MAA & + & + & Sialic acid, NeuNAc $\alpha 2-3 \mathrm{Gal}$ \\
\hline SNA & - & - & Sialic acid, NeuNAc $\alpha 2-6$ Gal(NAc) \\
\hline Con A & - & - & $\alpha$-Man, $\alpha$-Glc, $\alpha$-GlcNAc, branched mannoses \\
\hline DSA & - & nd & $\beta$-GlcNAc, $N$-acetyllactosamine repeats \\
\hline PHA-E & - & nd & Gal $\beta 1-4$ Glc NAc $\beta 1-2$ Man $\alpha 1-6 \rightarrow$ \\
\hline
\end{tabular}

+, positive staining; -, no staining; *staining after desialylation; nd, not determined.

(a)

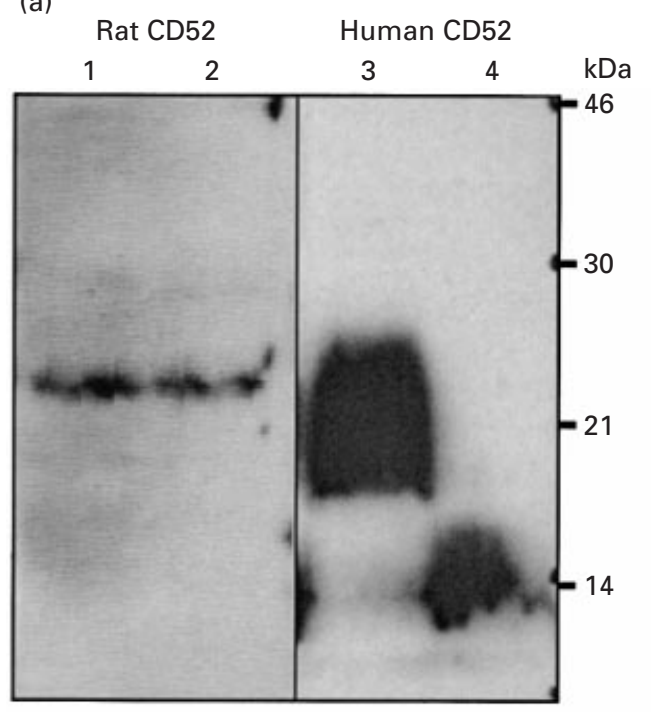

(b)

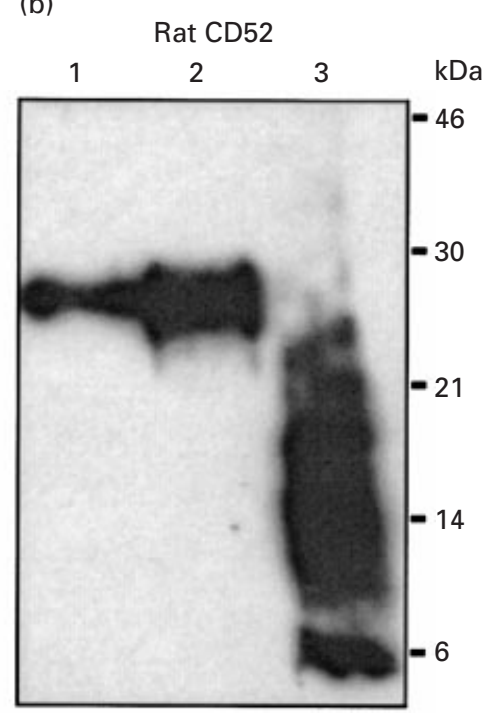

Fig. 8. Deglycosylation analysis of CD52 glycoprotein as enriched from cauda epididymidal fluid. (a) Western blot analysis of rat and human CD52 samples after PNGase F treatment. Lane 1: rat CD52 antigen after $24 \mathrm{~h}$ of incubation without PNGase F; lane 2: rat CD52 antigen after $24 \mathrm{~h}$ of incubation with PNGase F; lane 3: human CD52 antigen after $24 \mathrm{~h}$ of incubation without PNGase F; lane 4: human CD52 antigen after 24 h of incubation with PNGase F. (b) Western blot analysis of rat CD52 during chemical deglycosylation in a two-step procedure. Lane 1: untreated rat CD52 sample; lane 2: aliquot of the same sample after the first deglycosylation step; lane 3: aliquot of the same sample after the second deglycosylation step.

integral sperm membrane antigen was found in hamsters (Hoos and Olson, 1988).

GPI anchoring of rat CD52 was demonstrated by its sensitivity towards PI-specific PLC treatment, corroborating previous results obtained with this antigen (Moore et al., 1989; Eccleston et al., 1994). Acquisition of the highly glycosylated and lipid-anchored CD52 antigen is thus one of the few well-defined modifications that occur to the sperm membrane during epididymal passage. Sensitivity towards PI-specific PLC also implied that, in contrast to its human counterpart (Schröter et al., 1999), the GPI anchor of rat CD52 is not acylated at the 2-position of the inositol. Furthermore, there was no indication of significant structural differences between the antigen as extracted from whole cauda epididymidal tissue, fluid and spermatozoa.

Compared with other mammals (Krull et al., 1993; Pera et al., 1994), the rat epididymis produces relatively high amounts of CD52 mRNA in all parts of the organ (see Pera et al., 1997), whereas the corresponding glycopeptide was detected only in the cauda epididymidis. The appearance of the antigen with an $M_{r}$ of approximately 26000 and the glycoconjugate band was congruent with the appearance in 
the cauda epididymidis of CD52 mRNA molecules with a 'long' poly(A) tail (Pera et al., 1997), the direct relationship between both 'long' mRNA and translation product emphasized further by various types of animal treatment. The polyadenylation state of mRNA has long been implicated in message translation and RNA stability, the cap and $\operatorname{poly}(\mathrm{A})$ tail synergistically stimulating the initiation of translation (for a review, see Pestova and Hellen, 1999). Evidence has also been provided for the role of a reduction in the initiation of translation in stimulating deadenylation of mRNA (Schwartz and Parker, 1999). Results from the present study confirm regulation of the expression of rat CD52 antigen at a post-transcriptional level. Although no antigen could be detected in the proximal parts of the organ, initiation of translation occurred in the cauda epididymidis and seemed to imply stabilization of the CD52 mRNA poly $(A)$ tail.

During immunocytochemical staining, the antiserum was less specific and showed considerable crossreaction with testicular spermatozoa, although CD52 mRNA, and hence the CD52 antigen is not present in the testis (Kirchhoff, 1994, 1996; Pera et al., 1997). Therefore, this staining cannot reflect a precursor relationship of CD52related molecules originating at spermatogenesis, and must be due to nonspecific binding. The head region of immature testicular and caput epididymidal spermatozoa appeared susceptible to nonspecific binding and was also stained by negative control antisera. Some nonspecific binding to sperm proteins was occasionally observed during western blot analyses. The most prominent crossreaction appeared to be with an unrelated protein band of approximately 15-17 kDa, which did not contain any CD52-related peptide sequences. Polyclonal antiserum raised against an acidic (pl approximately 4.0) $26 \mathrm{kDa}$ protein of spermatozoa from rat cauda epididymidis (Olson et al., 1987) detected its antigen only over the flagellum.

Post-testicular uptake by the sperm membrane of the GPI-anchored CD52 does not rule out the possibility of carbohydrate modification within the epididymal duct lumen or on the sperm surface. Previous studies have indicated this mechanism (Hamilton et al., 1986; for a review, see Myles, 1993; Eccleston et al., 1994), and there is circumstantial evidence to support the plausibility of this idea. However, carbohydrate-modifying enzymes are usually intracellular enzymes that are active in vivo only as Golgi constituents, and their activity in male genital tract secretions has been assessed only in vitro. Moreover, it is not known whether the appropriate sugar donors are available from epididymal fluid. From the structural data presented by Schröter et al. (1999) after analysis of the $\mathrm{N}$ linked glycans of human CD52, it seems unlikely that extensive extracellular enzyme action could alter CD52bound carbohydrates in vivo.

Since the mature CD52 peptide sequences are so diverse among mammals (Kirchhoff, 1996; Kirchhoff and Hale, 1996), it has been suggested that they represent a scaffold for the presentation of the functionally more important carbohydrates. To date, only the carbohydrate structures of the human counterpart, as purified from pooled ejaculates, have been studied in detail (Schröter et al., 1999). Human CD52 has a single $\mathrm{N}$-glycosylation site that is completely occupied and carries more than 50 different highly heterogeneous and complex glycans. O-glycosylation of human CD52 has been excluded (Schröter et al., 1999). Although a highly conserved consensus site for $\mathrm{N}$ glycosylation was predicted from all CD52 sequences cloned thus far, including rat CD52 (Kirchhoff and Hale, 1996), lectin-binding and deglycosylation results from the present study do not support the presence of large and complex $\mathrm{N}$-linked carbohydrates of CD52 in rats. The NetOglyc program (Hansen et al., 1998) and other analyses of the purified glycopeptide (Eccleston et al., 1994) predict extensive mucin-type GalNAc O-glycosylation. In the molecular mass range of the immunoreactive protein band of the approximately $26 \mathrm{kDa}$, specific binding of Maackia amurensis lectin (MAA) and, after chemical desialylation, of Arachis hypogaea lectin (PNA), was observed, indicating the presence in rat CD52 of O-linked Gal $\beta 1-3-G a l N A c-$ containing carbohydrates which are terminally $\alpha 2-3$ sialylated. Most of the N-linked glycans of CD52 in human seminal plasma are also $\alpha 2-3$-sialylated (Schröter et al., 1999). However, the results from the present study do not support the idea of conservation of major structurally related glycans between human and rat CD52, but indicate profound species differences in CD52-linked carbohydrates in addition to differences in their peptide sequences and GPI anchor structures.

The authors thank S. Schröter, IHF, Hamburg, for helping with the lectin and deglycosylation studies. The authors are specifically grateful to E. Töpfer-Petersen, TiHo Hannover, and to S. Schröter for helpful discussions. This work was supported by the German Research Association (DFG-contract numbers Iv $4 / 7$ and $\mathrm{Ni}$ 130/15).

\section{References}

Altschul SF, Madden TL, Schäffer AA, Zhang J, Zhang Z, Miller W and Lipman DJ (1997) Gapped BLAST and PSI-BLAST: a new generation of protein database search programs Nucleic Acids Research 25 3389-3402

Bedford JM (1978) Influence of abdominal temperature on epididymal function in the rat and rabbit American Journal of Anatomy 152 509-522

Bergeron A, LaRue H and Fradet Y (1997) Biochemical analysis of bladdercancer-associated mucin: structural features and epitope characterization Biochemical Journal 321 889-895

Brown CR, van Glos KI and Jones R (1983) Changes in plasma membrane glycoproteins of rat spermatozoa during maturation in the epididymis Journal of Cell Biology 96 256-264

Duk M, Ugorski M and Lisowska E (1997) $\beta$-elimination of O-glycans from glycoproteins transferred to immobilon P membranes: method and some applications Analytical Biochemistry 253 98-102

Eccleston ED, White TW, Howard JB and Hamilton DW (1994) Characterization of a cell surface glycoprotein associated with maturation of rat spermatozoa Molecular Reproduction and Development 37 110-119

Foldesy RG and Bedford JM (1982) Biology of the scrotum. I. Temperature 
and androgen as determinants of the sperm storage capacity of the rat cauda epididymidis Biology of Reproduction 26 673-682

Goto Y, Amuro N and Okazaki T (1989) Nucleotide sequence of cDNA for rat brain and liver cytochrome c oxidase subunit IV Nucleic Acids Research 172851

Hamilton DW, Wenstrom JC and Baker JB (1986) Membrane glycoproteins from spermatozoa, partial characterization of an integral $M_{r}=24000$ molecule from rat spermatozoa that is glycosylated during epididymal maturation Biology of Reproduction 34 925-936

Hansen JE, Lund O, Tolstrup N, Gooley AA, Williams KL and Brunak S (1998) NetOGlyc: prediction of mucin type O-glycosylation sites based on sequence context and surface accessibility Glycoconjugate Journal 15 115-130

Hoos PC and Olson GE (1988) Characterization of a 23 kDa sperm-binding polypeptide of the golden hamster epididymis Biology of Reproduction 39 131-140

Jones R, Pholpramool C, Setchell BP and Brown CR (1981) Labelling of membrane glycoproteins on rat spermatozoa collected from different regions of the epididymis Biochemical Journal $200457-460$

Kirchhoff C (1994) A major messenger ribonucleic acid of the rodent epididymis encodes a small glycosylphosphatidylinositol-anchored lymphocyte surface antigen Biology of Reproduction 50 896-902

Kirchhoff C (1996) CD52 is the 'major maturation-associated' sperm membrane antigen Molecular Human Reproduction 2 9-17

Kirchhoff C (1998) Molecular characterization of epididymal proteins Reviews of Reproduction 3 86-95

Kirchhoff C and Hale G (1996) Cell-to-cell transfer of glycosylphosphatidylinositol-anchored membrane proteins during sperm maturation Molecular Human Reproduction 2 177-184

Kirchhoff C, Krull N, Pera I and Ivell R (1993) A major mRNA of the human epididymal principal cells, HE5, encodes the leucocyte differentiation CDw52 antigen peptide backbone Molecular Reproduction and Development 34 8-15

Krull N, Ivell R, Osterhoff C and Kirchhoff C (1993) Region-specific variation of gene expression in the human epididymis as revealed by in situ hybridization with tissue-specific cDNAs Molecular Reproduction and Development 34 16-24

Moore A, White TW, Ensrud KM and Hamilton DW (1989) The major maturation glycoprotein found on rat cauda epididymal sperm surface is linked to the membrane via phosphatidylinositol Biochemical and Biophysical Research Communications $160460-468$

Myles DG (1993) Sperm cell surface proteins of testicular origin: expression and localization in the testis and beyond. In Cell and Molecular Biology of the Testis pp 452-473 Eds C Desjardins and LL Ewing. Oxford University Press, Oxford

Olson GE and Hamilton DW (1978) Characterization of the surface glycoproteins of rat spermatozoa Biology of Reproduction 19 26-35

Olson GE, Lifsics MR, Winfrey VP and Rifkin JM (1987) Modification of the rat sperm flagellar plasma membrane during maturation in the epididymis Journal of Andrology 8 129-147

Pera I, Ivell R and Kirchhoff C (1994) Regional variation of specific gene expression in the dog epididymis as revealed by in situ transcript hybridization International Journal of Andrology 17 324-330

Pera I, Ivell R and Kirchhoff C (1996) Body temperature $\left(37^{\circ} \mathrm{C}\right)$ specifically down-regulates the messenger ribonucleic acid for the major sperm surface antigen CD52 in epididymal cell culture Endocrinology 137 4451-4459

Pera I, Derr P, Yeung C-H, Cooper TG and Kirchhoff C (1997) Regionalized expression of CD52 in rat epididymis is related to mRNA Poly(A) tail length Molecular Reproduction and Development 48 433-441

Pestova TV and Hellen CUT (1999) Ribosome recruitment and scanning what's new? Trends in Biochemical Sciences 24 85-87

Pouresmaeili F, Morales CR and Oko R (1997) Molecular cloning and structural analysis of the gene encoding PERF 15 protein present in perinuclear theca of the rat spermatozoa Biology of Reproduction 57 655-659

Schröter S, Derr P, Conradt HS, Nimtz M, Hale G and Kirchhoff C (1999) Male-specific modification of human CD52 Journal of Biological Chemistry $24729862-29873$

Schwartz DC and Parker R (1999) Mutations in translation initiation factors lead to increased rates of deadenylation and decapping of mRNAs in Saccharomyces cerevisiae. Molecular and Cellular Biology 19 5247-5256

Tulsiani DRP, Orgebin-Crist M-C and Skudlarek MD (1998) Role of luminal fluid glycosyltransferases and glycosidases in the modification of rat sperm plasma membrane glycoproteins during epididymal maturation Journal of Reproduction and Fertility Supplement 53 85-97

Yanagimachi R (1994) Mammalian fertilization. In The Physiology of Reproduction pp 189-317 Eds E Knobil and JD Neill. Raven Press, New York

Yeung C-H, Cooper TG, Oberpennig F, Schulze H and Nieschlag E (1993) Changes in movement characteristics of human spermatozoa along the length of the epididymis Biology of Reproduction 49 274-280

Yeung C-H, Schröter S, Wagenfeld A, Kirchhoff C, Kliesch S, Poser D, Weinbauer GF, Nieschlag E and Cooper TG (1997) Interaction of the human epididymal protein CD52 (HE5) with epididymal spermatozoa from men and cynomolgus monkeys Molecular Reproduction and Development 48 267-275

Zeheb R and Orr GA (1984) Characterization of a maturation-associated glycoprotein on the plasma membrane of rat caudal epididymal sperm Journal of Biological Chemistry 259 839-848

Received 21 June 2000.

Accepted 1 November 2000. 